\title{
Las competencias emprendedoras del periodista digital
}

Recibido: 03 de septiembre de 2015

Aceptado: el 22 de marzo de 2016

Publicado: 30 de noviembre de 2016

\author{
Martha Alicia Romero Echevarría \\ mromeroe@usmp.pe
}

Jacqueline Estrada Polar

jacquelineestradapolar@gmail.com

Universidad de San Martín de Porres (Perú)

Resumen: El impacto socioeconómico tiene efectos mundiales y los medios de comunicación no están exentos de ellos, ya que obedecen a tendencias globales, quedando en evidencia la necesidad creciente del desarrollo de las aptitudes y de habilidades personales y sociales de los profesionales de las Ciencias de la Comunicación, de manera que estén preparados para emprender sus propios proyectos, ya sean de manera individual o colectiva, con capacidad de planificar y llevarlos a cabo con integridad y confianza en sí mismos y que sean capaces de perseverar, sobre todo en el entorno digital actual, buscando elevar los índices de calidad. Ello implica ser capaz de alcanzar sus objetivos con responsabilidad, los retos en su desempeño y poder controlar sus reacciones bajo presión. En este sentido, en la presente investigación se ha realizado un análisis de las cualidades emprendedoras de los periodistas digitales para un desempeño exitoso, que tienen su principal fuente de formación profesional a las universidades del país.

Palabras clave: Capacidades, competencia, emprendimiento, gestión, habilidades y periodismo digital.

\begin{abstract}
The socioeconomic impact has global effects and Media is not exempt from them as they follow global trends, leaving growing need evidence of the development of aptitudes and skills (personal and social) from Communication professionals, so that they are prepared to undertake their own projects either individually or collectively, with ability to plan and carry out with integrity and self-confidence and are able to persevere, especially in today's digital environment, seeking to raise quality indexes, this means being able to achieve its objectives with responsibility, challenges in their performance and to control their reactions under pressure.
\end{abstract}


In this sense for this research it has conducted an analysis of the entrepreneurial qualities of digital journalists for successful performance, which have their main source of vocational training to universities.

Key words: Ability, Competence, Entrepreneurship, Management, Skills and Digital Journalism.

\section{Introducción}

En la actualidad, el rol del periodista se ha ido posicionando con la creciente tendencia de los medios virtuales, encontrando una nueva forma de hacer un periodismo más especializado, cubriendo necesidades sociales específicas, tales como los deportes, la economía, el medio ambiente, la educación, el entretenimiento, entre otras. La presencia de los profesionales en los medios digitales ha permitido que los periodistas tengan una mayor y mejor interacción con su público, de tal manera que hay una participación activa de los internautas, quienes muestran su acuerdo o desacuerdo con los contenidos de la información que se emiten por estos medios, permitiendo una evaluación de su desempeño casi inmediato y así generar o mejorar contenidos de la información que satisfaga a su público.

Con la evolución de la tecnología, se han generado nuevas posibilidades de desarrollo profesional independiente. Por tanto, los perfiles profesionales han adquirido nuevas competencias, añadiéndose valores cognitivos, técnicos y humanísticos a los profesionales de Ciencias de la Comunicación, quienes gozan de diversas especialidades y tareas que se conjugan en la búsqueda del bienestar tanto social como personal.

La competencia emprendedora de los periodistas digitales implica el desarrollo de características propias de personas con solvencia deontológica, con la libertad que su independencia le otorga, con conocimientos y habilidades empresariales que genere una cultura organizacional para un buen desempeño y permanencia en el medio digital. Además que la capacidad para desarrollar conocimientos por la necesidad de mantenerse bien informado; comprender, razonar y planificar para dar soluciones y conseguir resultados efectivos y eficientes; con capacidad de liderazgo para un trabajo cooperativo y en equipo.

El objetivo de la presente investigación reside en brindar luces sobre la nueva competencia emprendedora del profesional en periodismo, sobre la base de las características personales, sociales y tecnológicas que determinan una independencia laboral hacia un cambio económico y social, colocándolo a un nivel global, más especializado y más competitivo.

Para la elaboración del presente artículo se realizaron encuestas dirigidas a profesionales del periodismo que trabajan en los diferentes medios de comunicación y que realizaron sus estudios de pregrado en diferentes universidades. Asimismo, se llevó a cabo dos entrevistas a periodistas que han emprendido proyectos en los medios digitales y han logrado posicionarse por más de cinco años. Además, se revisaron los contenidos curriculares de la carrera de Ciencias de la Comunicación o Periodismo de tres universidades de la ciudad de Lima. 


\section{Competencia profesional}

La cada vez más creciente expectativa por alcanzar estándares de calidad en las organizaciones (para poder colocarse a la vanguardia que los lleva a la competitividad en los mercados locales, nacionales e internacionales) conlleva a que los profesionales en Periodismo estén preparados en cuanto a sus conocimientos, intereses y atributos personales que son indispensables para el desarrollo de la competencia laboral. En este sentido, Gonczi y Athanasou conciben la competencia profesional "como una compleja combinación de los atributos (conocimientos, actitudes, valores y habilidades) y las tareas que se tienen que desempeñar en determinadas situaciones y que involucra a las diferentes dimensiones de la persona" (ápud Gómez, 2005: 47), este concepto integrador relaciona las condiciones personales con el quehacer profesional, de manera que planifique sus acciones teniendo en cuenta el contexto donde se desarrolla, la cultura organizacional y un comportamiento ético en su desempeño.

Con respecto a las competencias de egreso de las universidades, Larraín y González (2006: 13) definen la competencia "como la capacidad de actuar adecuadamente, respaldado por los conocimientos pertinentes y en coherencia con los principios éticos que sustenta quien la ejerce". En el Proyecto Tuning (Education and Culture Socrates-Tempus, 2006) las competencias son referidas con una orientación integradora, que considera las capacidades (que combinadas con los atributos) conllevan hacia un desempeño competente como parte del producto del desarrollo de las competencias cognitivas, procedimentales y actitudinales en el contexto universitario. Las competencias y las destrezas están referidas a la adquisición del conocimiento teórico en el campo académico, al saber qué hacer y cómo actuar con esos conocimientos, al saber cómo ser consigo mismo y con los demás en el contexto que le rodee.

Tobón (2006) hace hincapié en que las competencias están definidas de acuerdo con lo que las empresas requieren del personal que labora o va a laborar en ella, con el fin de optimizar el desempeño de las personas que en ella se desenvuelven para la consecución de una mejor calidad en la producción, haciéndose competitiva en el mercado. Para ello, sugiere que el diseño del currículo universitario esté acorde con la gestión de la calidad que es exigida con mayor ahínco por las empresas y la certificación universitaria. De allí que las competencias requeridas por el entorno estén orientadas a un ejercicio profesional que vaya de acuerdo con las características del contexto actual (tanto local, nacional e internacional) y a las tendencias de la profesión, proyectando los cambios sociales, políticos y tecnológicos.

\subsection{Competencia emprendedora}

El vocablo "emprendimiento" proviene del latín in prendere, inicialmente usado para referirse a las diligencias de aventureros y operaciones militares. Casi al mismo tiempo, en el siglo XVI, en Francia "se origina el verbo francés entrependre que significa 'encargarse de"” (Alcaraz, 2011: 2). De esta forma, el significado comprende el estar listo a tomar decisiones o a iniciar algo, haciendo referencia a los aventureros que viajaban buscando nuevas oportunidades. Desarrollar un concepto acerca de la persona emprendedora implica que la persona es la que cumple con un perfil determinado para tomar acciones frente a decisiones 
de autogestión laboral, de manera que le permite el desarrollo de competencias personales, sociales y profesionales para "precisar y lograr sus objetivos planteados" (ibidem).

Al referirnos a las competencias emprendedoras, el concepto se asocia con hacer empresa y las cualidades necesarias para colocarse a la vanguardia de los mercados locales, nacionales e internacionales. Para ello, se necesita que los profesionales estén preparados en cuanto a sus conocimientos, intereses y atributos personales que son parte de la competencia laboral. En este sentido. En este sentido, Gómez (2005) refiere que actualmente la prioridad de las organizaciones se enfoca en que sus recursos humanos estén preparados para desenvolverse de manera óptima, con buena actitud, valores personales y profesionales para un buen desempeño y permanencia de la organización.

La persona que desarrolla la competencia emprendedora es poseedora de características personales que pueden ser innatas o adquiridas de manera empírica y/o científica, lo cual le permite cumplir con sus objetivos personales, sociales y económicos de manera eficiente y eficaz. Al respecto, Harper (1991) identifica al emprendedor como

"una persona capaz de revelar oportunidades y poseedor de las habilidades necesarias para elaborar y desarrollar un nuevo concepto de negocio [...] tiene la virtud de detectar y de manejar problemas y oportunidades mediante el aprovechamiento de sus capacidades y de los recursos a su alcance, gracias a su confianza" (ápud Alcaraz, 2011: 2).

\subsection{El perfil del emprendedor peruano}

Serida y otros (2015: 2) sostienen que, en el proceso del desarrollo económico, la mayor propensión de las personas que crean empresas se encuentra entre los 25 y 44 años de edad (figura 1), estableciendo diferencias entre los emprendedores de las economías con base en los recursos y eficiencia son más jóvenes, en comparación con las basadas en innovación, que provienen de edades intermedias.

Figura 1: Distribución porcentual de los emprendedores en etapa temprana según la edad.

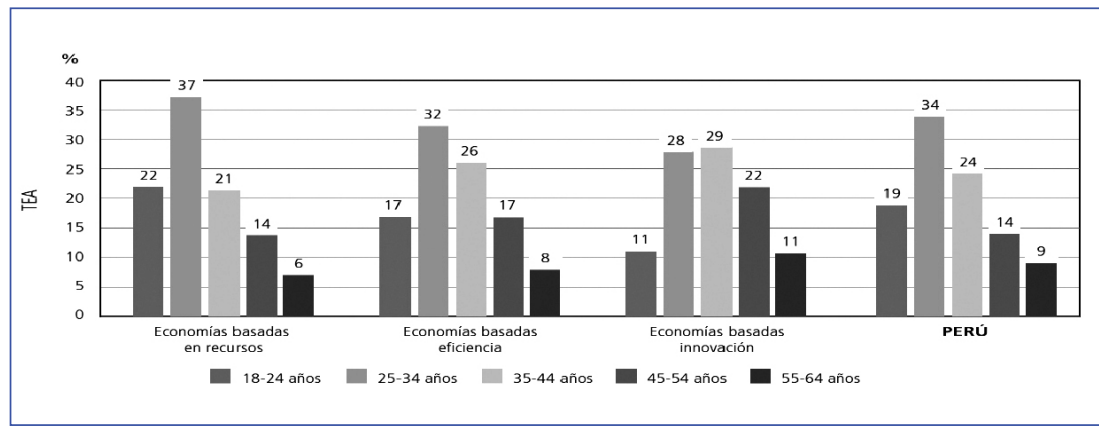

Fuente: Serida y otros (2015: 41). 
Puede observarse específicamente que en el Perú la mayoría de emprendedores se inicia en el segmento de 25-34 años. Tomando en cuenta estos resultados, podemos establecer que en la mayoría de los casos la profesionalización se logra a esa edad. Cabe resaltar que (en relación a las razones que los impulsan a emprender) los que nacen motivados por la propia necesidad por lo general son de más edad, mientras que los profesionales con competencias emprendedoras se preparan, planifican, organizan y ejecutan sus planes de desarrollo empresarial-profesional y lo hacen a más temprana edad.

Un dato bastante interesante que se encontró en dicho estudio fue la diferencia por género, donde la participación de la mujer en emprendimientos en etapa temprana en el Perú ha ido en aumento. Sin embargo, no ha crecido al mismo ritmo que los varones, pero se puede observar que en anteriores estudios la diferencia era mayor y en la actualidad la brecha se ha acortado, de tal manera que se espera que para los próximos estudios la relación baje, se iguale o se superen las posibilidades de desarrollo independiente para la mujer profesional del periodismo.

Con respecto a la educación, cada vez hay un mayor número de personas emprendedoras con educación superior que inicia nuevos negocios, no sólo como un medio para sobrevivir, sino para aprovechar las oportunidades que surgen mercado nacional. De allí que actualmente los emprendedores se preocupen por tener una mayor preparación educativa, la cual influye en la forma cómo distinguen las oportunidades y se pueden beneficiar de ellas.

Los factores motivacionales que le permiten a la persona lograr despegar en busca de su independencia laboral y económica para posicionarse en el mercado laboral y perseverar en él son la oportunidad y la necesidad. Al respecto, Serida y otros (figura 2) destacan la presencia de los emprendedores que son profesionales, cuyas competencias personales fueron fortalecidas en su universidad de origen. Las personas que no alcanzaron terminar la educación básica se han posicionado en el mercado como emprendedores por necesidad.

Figura 2: Nivel educativo de los emprendedores en etapa temprana, según la motivación para emprender.

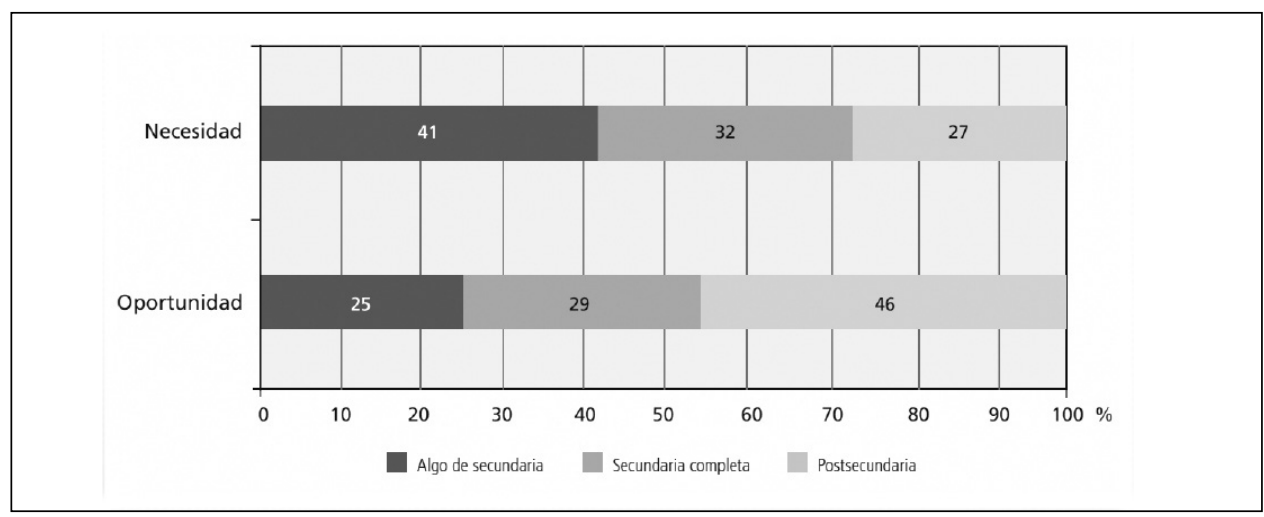

Fuente: Serida y otros (2015: 46). 
Las competencias emprendedoras de los profesionales en Ciencias de la Comunicación deben formar parte de su formación integral para la creación de empresas, a fin de aprovechar la oportunidad que los medios de comunicación digital ofrecen. Así, se debe direccionar el desarrollo de habilidades empresariales y sociales desde los primeros años de formación profesional. Acerca de las actitudes y percepciones, es muy importante el concepto que la sociedad pueda crear de los emprendedores, ya que muchos pueden servir de ejemplo para que otros se inclinen hacia la aventura emprendedora. El valor que la sociedad le otorga al emprendedor puede ser determinante para que otras personas decidan prepararse para llevar una aventura emprendedora en campos deseados, pero no resueltos.

No es suficiente con percibir las oportunidades y sentirse capaz de aprovecharlas. Es importante que el emprendedor aprenda vencer sus miedos y asumir riesgos que le proporcionen la seguridad de afianzarse en su proyecto. Siempre existen las posibilidades de éxito como de fracaso, pero ninguna de las dos debe representar un problema, sino una oportunidad para que el negocio prospere. En cuanto al éxito, este puede ser producido circunstancialmente. Por ello, hay que estar vigilantes y tomar medidas para que sea duradero y sólo se mantendría cuando innovamos de manera permanente. El fracaso también tiene sus ventajas cuando son evaluadas de manera correcta y sin apasionamientos, porque permite tomar acciones correctivas o disuasivas, según sea el caso.

En el Perú existen actitudes positivas al emprendimiento (figura 3), así tenemos las ocasiones que nos brindan el espacio social y el desarrollo de las competencias emprendedoras que proporcionan una visión más amplia para estar preparados para emprender con mayor seguridad. El miedo al fracaso tiene una tendencia negativa que lleva a poner límites que son muchas veces inexistentes y que los que lo tienen los perciben como probables, de manera que la actitud emprendedora se ve atada de las manos para seguir con el proyecto encontrando las formas de evadirlas.

Figura 3: Evolución de los indicadores de actitudes emprendedoras en el Perú.

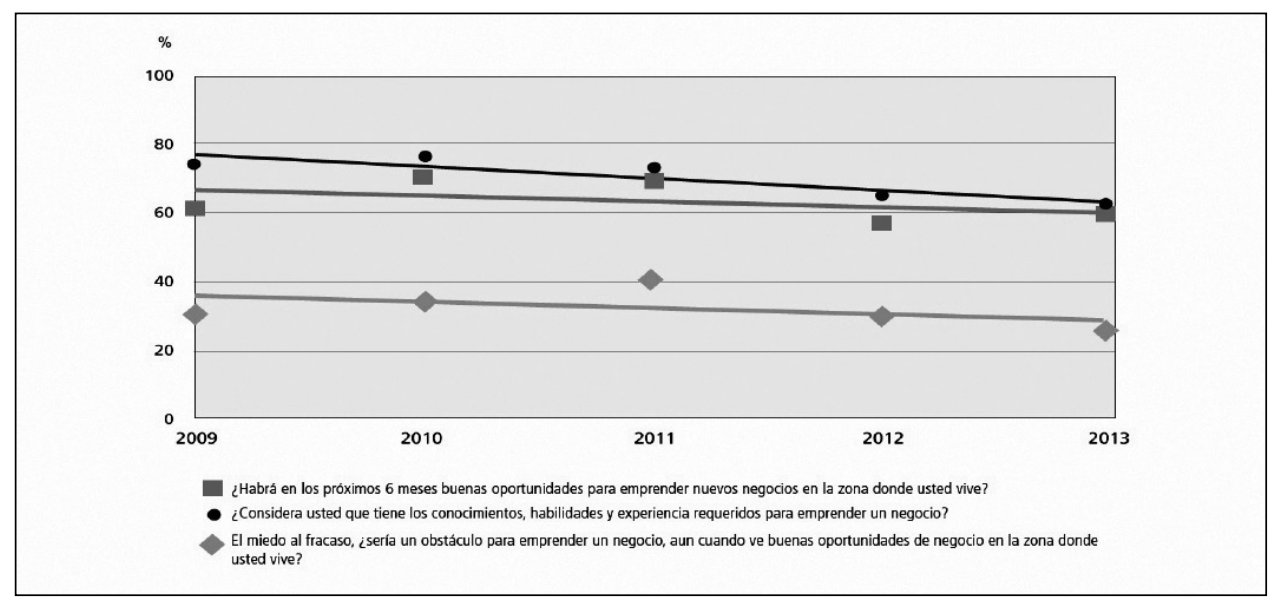

Fuente: Serida y otros (2015: 53). 


\subsection{Características del emprendedor}

El emprendedor tiene ciertas características que lo diferencian de las demás personas y que le sirven para poder alcanzar sus objetivos. No se ha logrado establecer si estas características personales son innatas, heredadas o si se adquieren en el proceso de desarrollo desde la infancia (comportamiento y actitudes de los padres, la educación y/o la sociedad). Así, se sugiere que las personas emprendedoras dependen de las características emprendedoras de los padres y estas pueden ser transmitidas genéticamente, en especial a las hijas, quienes serían más propensas a gestionar sus propios empleos que los hijos varones (Casero y Cullell, 2013: 683).

Esta postura es cuestionable: Serida y otros (2015) afirman que existen 6 mujeres por cada 10 varones que son emprendedores, de manera que el varón tiene más iniciativas para emprender en nuevas oportunidades de desarrollo profesional. Esto probablemente esté determinado porque aún el Perú conserva taras machistas o porque las mujeres asumen roles diferentes que demandan su atención y responsabilidad a más temprana edad que los hombres.

En suma, los rasgos emprendedores son aprendidos en el proceso de desarrollo del individuo que va adquiriendo cualidades particulares y son reforzados por la necesidad o por la oportunidad, tales como la innovación, la proactividad, ser eficaz, desarrollar la tolerancia a la frustración, tener capacidad de decidir, la toma de riesgos. Según Rauch y Frese, "algunos rasgos de la personalidad pueden tener una influencia directa a la hora de determinar la aparición y activación de una actitud de emprendimiento" (ápud Casero y Cullell, 2013: 682).

Existen muchas características que hacen que el emprendedor alcance el éxito. La siguiente es una lista de las diez principales características que se suele encontrar en los emprendedores exitosos:

- Creatividad: el periodista debe tener la capacidad de poder crear o producir nuevas cosas y encontrar la manera de realizar o producir información de manera distinta, con capacidad para resolver problemas de manera diferente. Liberal y López y Recio hacen referencia que la creatividad es un proceso mental que le permite al emprendedor tomar acciones para convertir los hechos en oportunidades, de manera única, que sea diferente pero determinantemente bueno, que sirva para que un emprendedor en el medio digital se desempeñe reinventándose cada día de diferentes formas, con novedades para sus cibernautas y pueda mantener su atención de forma duradera (ápud Alcaraz, 2011).

- Liderazgo: el profesional emprendedor debe desarrollar la capacidad para poder influir en los demás, incentivando y motivando a un equipo de trabajo, para llegar alcanzar un objetivo o una meta. Cardoso refiere que el líder debe estar preparado para poder reconocer las necesidades de desarrollo y poder planificar acciones para lograr los objetivos planteados anticiparse a los problemas y resolverlos conforme se presenten (ápud Páez y García, 2011). Además de tener la capacidad para comunicarse eficazmente y ser capaz de trabajar en equipo para alcanzar las metas. 
- Innovación: siendo necesario para el emprendedor crear una ventaja competitiva de su producto o servicio que te permita diferenciarlo de los demás, entonces el periodista digital debe estar preparado para hacer esa diferencia que lo hace único. Metzgel y Donaire definen al innovador como una persona capaz de hacer la diferencia en los productos y servicios que brinda haciéndolos únicos para los consumidores (ápud Alcaraz, 2011). Es así que el periodista digital emprendedor debe estar preparado para ofrecer nuevas formas de llegar a un público y ofreciéndole cosas nuevas para mantener latente su interés y de esa manera mantenerlo fidelizado.

- Asumir riesgos: al estar listo para asumir retos, los profesionales se preparan para tomar decisiones con una actitud que permite al emprendedor levantarse ante los errores y volver a empezar nuevamente con nuevas ideas y estrategias para alcanzar sus metas, resolviendo de manera efectiva y eficiente los acontecimientos que se susciten de su proyecto en práctica de sus planes de acción. Al respecto, Baty manifiesta que tomar riesgos es una capacidad inherente al emprendedor siendo esta una forma de ganar y aunque las cosas no salgan del todo bien los emprendedores aun así ganan (ápud Alcaraz, 2011).

- Proactividad: es necesario que la persona emprendedora no tenga conductas reactivas, debido a que ante problemas puede tomar decisiones que le afecten de manera considerable. Por tanto, ser proactivo hace que tenga la iniciativa y decidir qué hacer para que su negocio pueda superar los problemas y las dificultades de la mejor manera, sacando provecho de los resultados óptimos o adversos que aparecen producto de emprender nuevos retos.

- Eficacia: esa cualidad permitirá al emprendedor lograr los objetivos propuestos, por la seguridad que adquiere cuando toma en cuenta todos los factores que están alrededor de una decisión tomada, de manera que haga uso ce sus talentos para lograr aquello que se propone en la empresa que está emprendiendo y pudiendo resolver los problemas que se presenten.

- Tolerancia: aunque en ocasiones sus colaboradores fallan, las personas emprendedoras deben desarrollar las habilidades para controlarse y responder adecuadamente, logrando motivar y no desanimar a las personas que lo acompañan en el proyecto. Un concepto a tomar en cuenta es la "tolerancia a la frustración", porque implica la capacidad de controlarse y fortalecerse de los resultados no esperados por negativos que sean.

- Perseverancia: es la constancia que los emprendedores le ponen a todo aquello que anhelan conseguir, ser perseverante es importante ya que es la fuerza que le permitirá al emprendedor trabajar día a día para alcanzar sus objetivos a pesar de las circunstancias internas o externas o situaciones problemáticas que se le presenten en la realización de sus tareas.

- Trabajo en equipo: a la hora de emprender, es importante el trabajo en equipo de manera organizada, haciendo uso de las habilidades y cualidades de cada integrante del grupo 
para poder alcanzar una meta. Cuando los miembros que acompañan al profesional en la empresa que está emprendiendo, cada uno (de forma interdependiente) va sumando con sus conocimientos y experiencias, haciendo suyos los objetivos, imprimiendo entusiasmo y compromiso con el desarrollo del proyecto.

- Autoconfianza: esta es una de las capacidades más importantes en el profesional emprendedor: de creer en sí mismo y en sus habilidades para lograr sus metas, de tal manera que pueda poner en marcha el proyecto utilizar todos sus recursos personales que con las características anteriormente mencionadas se complementan.

En la presente investigación, se han tomado los aspectos más relevantes del periodista digital emprendedor, los cuales se consideran como parte de las competencias que no podrían dejar de tener:

- Capacidad de síntesis: es una serie de recursos que permite a una periodista juntar distintas realidades y, a partir de ellas, crear conocimientos e información que pueda brindar a su público objetivo.

- Inteligencia emocional: es el tipo de inteligencia que le permite al periodista conectar no sólo con sus compañeros de trabajo, sino también con su audiencia. Esto le permitirá crear una relación de confianza con sus colaboradores, reflejándose en la realización de su trabajo y con los internautas, permitiéndole una mejor interacción.

- Proactividad: que le permitirá al periodista brindar información para dar solución a los problemas que se presenten de manera creativa e innovadora, facilitándose el trabajo en equipo y los objetivos trazados.

- Inteligencia social: es la capacidad de relacionarse con otros en forma pacífica y armoniosa. Permite al profesional tener en cuenta las cualidades personales del público al cual se dirigen y reconocer sus gustos y preferencias.

- Razonamiento computacional: es indispensable para el buen desempeño del trabajo del periodista digital. Implica el desarrollo de habilidades que permitan el manejo de herramientas para la producción y difusión de los contenidos digitales.

- Análisis de medios: los periodistas digitales cuentan con la capacidad de evaluar las distintas métricas de su sitio web y el feedback e interactuar con el público al que se dirige.

- Interdisciplinariedad: es la capacidad que posee el periodista de poder trabajar en conjunto con profesionales de distintas especialidades y coordinar con ellos para unir y complementar sus conocimientos con el fin que el público esté bien informado.

- Trabajo en equipo: en la ejecución del trabajo, el periodista tendrá que unir talentos con las personas que trabajan con él o ella, con el fin de lograr alcanzar una misma meta u objetivo. 
- Liderazgo: al periodista se le atribuye un gran poder por medio de las comunicaciones. Por lo tanto, debe desarrollar habilidades para motivar y guiar al grupo hacia un objetivo determinado.

- Autoconfianza: es la capacidad que el periodista desarrolla para creer en sí mismo, de sentirse seguro y de tener la fuerza interior que le ayude a lograr sus objetivos y superar cualquier barrera que se le presente.

\subsection{Barreras que tiene que superar el emprendedor}

Al momento de emprender una empresa, surgen una serie de limitaciones o ideas que generan actitudes que no dejan accionar a las personas. Estas dificultades pueden considerarse como los paradigmas y creencias limitantes para ejercer el emprendimiento y se van interiorizando desde el entorno, generando inseguridad en las personas.

De las barreras identificadas por Secretaría Pyme y Desarrollo Emprendedor (2014: 50), mencionamos las que consideramos más limitantes para el emprendedor:

- Fuimos educados para buscar empleo: la falta de cultura emprendedora hace que el emprendedor no sienta el apoyo de su entorno al momento de iniciar una idea de negocio. De la misma manera, es necesario que el emprendedor entienda que asumir riesgos y lidiar con posibles fracasos es parte de la tarea de iniciar un negocio.

- Dificultad para armar un equipo de trabajo: el equipo es muy importante a la hora de emprender un proyecto, pero el emprendedor está más concentrado en ganar dinero rápidamente y muchas veces no le da la importancia que requiere la selección de un buen equipo de trabajo.

- Muchas ideas de negocio no se ajustan a las necesidades del mercado: encontrar satisfacer una necesidad es clave al momento de iniciar un negocio, la clave es encontrar una oportunidad al momento de brindar una solución a alguna necesidad que se presenten.

- Problema para armar redes de contacto: establecer redes resulta clave al momento de emprender. Esto le permitirá al emprendedor crecer hacia otros mercados. Esta labor es muy difícil de hacer y muchas veces el emprendedor termina por desistir de su proyecto.

- Falta de financiamiento: muchas veces el emprendedor no sabe cómo buscar financiamiento. Es importante que haga un listado con las posibilidades como ahorros, préstamos de amigos, de bancos, entre otras.

\section{El periodista digital}

En el Perú, la transición del periodismo tradicional a la digital no fue fácil, ya que la mayoría de los diarios debían rediseñar la información e introducirse al mundo de la tecnología, 
en la capacitación de los profesionales y contratación del personal técnico. La actitud de los periodistas (acostumbrados a la producción de noticias en forma clásica) impedía la incorporación de herramientas digitales y nuevos métodos de producción de contenidos. Al respecto, Yezers'ka (2008: 215) nos dice que los periodistas peruanos (al igual que en otros países que ya han iniciado su trabajo con la digitalización hace algún tiempo) han descubierto "los secretos de la programación e informática, en la interactividad, en las claves de multimedia y la narración hipertextual".

El periodista digital es un profesional en Ciencias de la Comunicación que trabaja contenidos periodísticos en un medio digital con conocimientos avanzados en programas de diseño web y aplicaciones multimedia, herramienta de búsqueda y redacción para la Internet (ibídem). A través de la Internet, el periodista puede encontrar desde sus fuentes de información hasta herramientas que le permita editar un video o le facilite la transcripción de un audio. La Internet también le ayudará a difundir información y las redes sociales le permiten al periodista estar en contacto con el público que le sigue, saber qué información desean y resolver sus consultas y dudas. Esto permite al profesional obtener información valiosa sobre los gustos y preferencias del internauta y tener ideas para nuevos portales de información especializada e incursionar en el emprendimiento digital.

En la actualidad, los periodistas comparten sus labores entre los medios tradicionales y digitales. Es por eso que se han transformado en profesionales versátiles, capaces de adaptarse a los nuevos conocimientos y nuevas formas de trabajo. Para Rubio, la mayoría de los periodistas desarrollan sus habilidades en las plataformas multimedia y en los medios tradicionales en los que existen profesionales que promueven las plataformas y editan la información, asegurando que lo que debe cambiar es la nominación, ya que "el periodista no es digital, sino multimedia, macromedia, multiplataforma” (ápud Salaverría, 2016: 322).

Además de todos los conocimientos adquiridos durante sus años de estudio y su formación deontológica, el periodista debe estar dispuesto a aprender y a experimentar con nuevas herramientas que se puedan encontrar en la Internet, tanto en lo escrito como en lo audiovisual, las mismas que le facilitarán su trabajo en la difusión de la información que desean dar a conocer. De la misma manera, debe desarrollar también capacidades proactivas, de innovación y trabajo en equipo, a fin de lanzarse a la aventura emprendedora.

\subsection{Perfil del periodista digital}

Con la llegada de las nuevas tecnologías, el trabajo de periodista ha cambiado y ha tenido que desarrollar habilidades y conocimientos que le permitan continuar con su trabajo de forma eficiente. Arroyo (2011: 3) afirma que un periodista digital es un profesional que trabaja en un ambiente digital, donde la hipertextualidad, la multimedialidad y la interactividad determinan la producción de informaciones.

Si bien es cierto que el periodista no tiene que convertirse en un técnico, es necesario que el profesional cuente con conocimientos de las herramientas digitales que lo ayuden en la producción de su labor periodística y que haga de estos recursos, parte integral de su 
trabajo diario. No debemos de olvidar que la principal función del periodista (tanto en los medios tradicionales como digitales) es ser guardianes de la veracidad de sus contenidos, siendo obligación del periodista contrastar y verificar la información.

Al respecto, Arroyo (2011) añade que es indispensable que los periodistas estén preparados para enfrentar la gran cantidad de información y tener la agilidad para la producción informativa. Salaverría (2004) asegura que estos medios digitales ya empezaron a delinear una nueva forma de comunicarse, con un lenguaje propio, con nuevas formas lingüísticas que las personas están incorporando de manera cotidiana y los periodistas no pueden dejar de lado y que deberán de asimilarlo.

La participación de los ciudadanos se ha ido ampliando: los internautas son ahora capaces de producir contenidos relevantes para los cibermedios. Esto no anula el papel del periodista, ya que el profesional tomará en cuenta lo que los ciudadanos puedan aportar y seleccionará lo que es de interés para su grupo objetivo, con un compromiso moral y ético hacia al público al que se dirige. De esta forma, se convierte en un elemento indispensable que garantiza la calidad de la información brindada al internauta.

Por ese motivo, las empresas periodísticas demandan profesionales versátiles, con capacidad de desenvolverse en diferentes tareas; un profesional con preparación multimedia y creativa, capaz de enfrentar a la competencia con propuestas diferentes y originales.

"El periodista del futuro ha de ser un profesional capaz de adaptarse a las diferentes formas de trabajo, capacitado en nuevas tecnologías y con buena disposición para trabajar en equipo. Un periodista con una sólida formación y con una actualización permanente" (Arroyo, 2011: 5).

Pero no es suficiente que el profesional cuente con conocimientos periodísticos: es necesario también un compromiso moral con el público al cual se dirige, que le permita realizar su trabajo bajo las normas éticas del periodismo. Para las empresas periodísticas, es importante contar con un profesional de formación permanente: no basta con la obtención del título, la preparación debe ser continua y durar toda la vida. Además, el profesional debe adecuarse a los cambios tecnológicos y a las exigencias que obliga el mercado laboral, estando en constante capacitación y adaptándose a los cambios que se producen con la tecnología (ibídem: 8).

\subsection{Pasos para emprender un medio digital}

Para iniciar un medio digital, Serrano (2011) refiere que es necesario elaborar un bosquejo donde se plasmen las ideas principales, con un análisis de factibilidad, a fin de tener en cuenta con qué recursos se cuenta para poner en marcha el proyecto.

- El primer paso consiste en tomar en cuenta las características del medio y el proceso de producción de la información, analizándose sus propias fortalezas y debilidades, al igual que formar un equipo de trabajo con el cual se pueda contar para lograr los objetivos. 
- En seguida, se emprende un análisis de los posibles competidores, cuáles son los costos que implica el proyecto y la constitución de la empresa.

- Se lanzan pruebas iniciales para ensayar la eficacia y se hacen los ajustes necesarios con el fin de satisfacer al público al cual se dirige el programa.

- Crear un plan de ventas que permita el sostenimiento del medio digital.

- Implementar un plan de marketing digital que nos permita difundir nuestro sitio web.

Es importante tener en cuenta que la implementación de un medio digital es muy parecida al nacimiento de cualquier otro emprendimiento, teniendo en cuenta que la materia prima será la información que se difunda y que se debe mantener a la expectativa de los requerimientos de los internautas y próximo a los cambios en la información, los cuales son constantes en el ambiente digital.

\section{Resultados}

Para la elaboración del presente artículo se realizaron encuestas dirigidas profesionales del periodismo que estudiaron la carrera profesional en diferentes universidades del país y que actualmente trabajan en diferentes medios de comunicación. Sus edades oscilan entre los 26 y 54 años. Del mismo modo, se llevó a cabo una entrevista a dos periodistas emprendedores dentro del ambiente digital y que han logrado posicionarse por más de 5 años.

Además, se revisaron los perfiles de egreso para la carrera profesional de Ciencias de la Comunicación o Periodismo de tres importantes universidades del Perú (Universidad de San Martín de Porres, Universidad de Lima y Universidad de Piura) elegidas al azar, sólo considerándose que contaran con la especialidad de Periodismo.

De los resultados obtenidos por medio de los cuestionarios, se clasificaron en dimensiones y se han vertido los resultados más relevantes, en opinión de la muestra que estuvo constituida por periodistas que colaboraron con la investigación:

4.1. En su formación profesional desarrolló sus capacidades y habilidades que lo hicieron sentir seguro para emprender en una empresa de forma independiente. 
Figura 4: Al egresar estaban capacitados para emprender.

\begin{tabular}{|c|c|c|c|}
\hline & FRECUENCIA & PORCENTAJE & PORCENTAJE ACUMULADO \\
\hline Casi siempre & 5 & $21 \%$ & $21 \%$ \\
\hline A medias & 8 & $33 \%$ & $54 \%$ \\
\hline Casi nunca & 11 & $46 \%$ & $100 \%$ \\
\hline Total & 24 & $100 \%$ & \\
\hline
\end{tabular}

Fuente: Elaboración propia.

La mayoría de profesionales opinan que cuando egresaron de las aulas universitarias no tenían desarrolladas las competencias necesarias para poder emprender sus propios negocios. Este resultado probablemente sea porque las competencias de los profesionales han ido cambiando de acuerdo a las necesidades sociales y la vertiginosa evolución que ha sufrido la ciencia y tecnología, lo que ha permitido encontrar nuevos nichos de desarrollo para las Ciencias de la Comunicación, siendo el medio digital el que se va posicionando cada vez más, con una nueva forma de hacer noticia que es interactiva para los públicos a los cuales se dirigen.

Hacer empresa necesita del desarrollo de cualidades específicas para colocarse a la vanguardia de los mercados locales, nacionales e internacionales; siendo así que los profesionales deben estar preparados en cuanto a sus conocimientos, intereses y atributos personales que son parte de la competencia laboral y social.

4.2. Durante sus estudios en pregrado llevó cursos que lo prepararon para trabajar en gestión en empresas del rubro.

Figura 5: Al egresar estaban listos para gestionar empresas.

\begin{tabular}{|l|r|r|r|}
\hline & FRECUENCIA & PORCENTAJE & PORCENTAJE ACUMULADO \\
\hline Casi siempre & 6 & $25 \%$ & $25 \%$ \\
\hline A medias & 8 & $33 \%$ & $58 \%$ \\
\hline Casi nunca & 10 & $42 \%$ & $100 \%$ \\
\hline Total & 24 & $100 \%$ & \\
\hline
\end{tabular}

Fuente: Elaboración propia.

Se puede observar que los profesionales no sienten que han sido preparados para gestionar o dirigir empresas en el rubro de las comunicaciones, lo que se contrasta con otra de las preguntas, donde se evidenció que, cuando estudiaron en la universidad, la gran mayoría se preparaba pensando en trabajar para algún medio, pero no se proyectaba para dirigir o gestionar una empresa. De los 24 encuestados, sólo 4 han emprendido algún negocio en el rubro de las comunicaciones, mientras que 3 de estos han asumido una gerencia o jefatura en algún momento de su desarrollo profesional. 
4.3. En la actualidad, está de acuerdo con que los egresados están preparados para usar las multiplataformas

Figura 6: Competencias computacionales en los egresados.

\begin{tabular}{|l|r|r|r|}
\hline & FRECUENCIA & PORCENTAJE & PORCENTAJE ACUMULADO \\
\hline Casi siempre & 19 & $79 \%$ & $79 \%$ \\
\hline Es probable & 4 & $17 \%$ & $96 \%$ \\
\hline Casi nunca & 1 & $4 \%$ & $100 \%$ \\
\hline Total & 24 & $100 \%$ & \\
\hline
\end{tabular}

Fuente: Elaboración propia.

Los profesionales en periodismo manifiestan que, en la actualidad, la mayoría de los egresados desarrolla sus competencias multimedia. Esto les facilita el ingreso y manejo de la información, estando actualizados y preparados para asumir con confianza los retos impuestos por el desarrollo de las competencias profesionales que son también sociales, ya que la Internet provee al periodista fuentes de información y hasta herramientas para editar un video o transcribir un audio; siendo el soporte para difundir información, manteniendo contacto directo con el público que le sigue para conocer la información desean y también para resolver consultas y dudas.

4.4. Indique cuáles son las competencias que adquirieron en el campo de desarrollo profesional y cuáles son las que desarrollaron en su proceso de formación profesional en las aulas universitarias.

Figura 7: Competencias emprendedoras aprendidas.

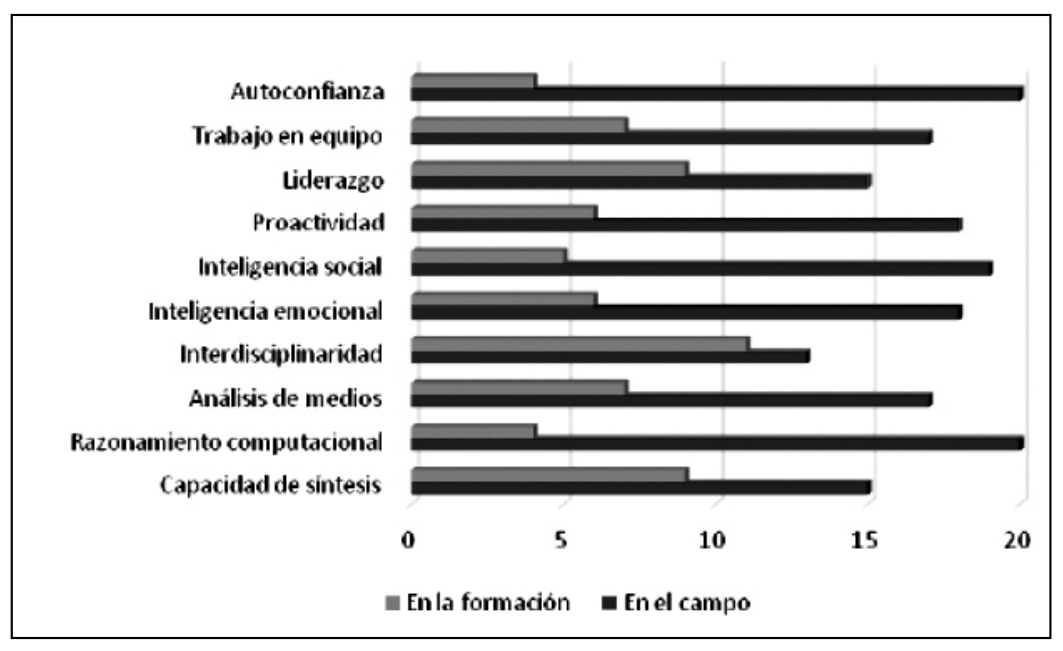

Fuente: Elaboración propia. 
Los resultados indican que las competencias emprendedoras que necesita el periodista digital han sido desarrolladas con el tiempo de experiencia profesional, por la necesidad y según se fueron presentando, debiendo ser tomado en cuenta para que los nuevos emprendedores puedan practicarlas desde las aulas universitarias, ya que con el tiempo irán apareciendo otras necesidades, las cuales los llevarán a actualizarse de manera continua.

\section{Conclusiones}

Los resultados obtenidos indican que los profesionales de Ciencias de la Comunicación deben estar preparados para posicionarse en el mercado laboral que cada vez es más competitivo, así como para gestionar en las empresas comunicativas que los requieran o para crear sus propias empresas, lo que implica tener una mayor y mejor preparación para enfrentar con éxito el mundo de las comunicaciones.

En las universidades del Perú se pueden distinguir que las carreras profesionales de Ciencias de la Comunicación tienen perfiles bien definidos en cuanto a las competencias emprendedoras del periodista digital. En la USMP existe el perfil específico en periodismo para las multiplataformas, que considera la preparación para la administración de proyectos de comunicación propios. En la Universidad de Lima, el estudiante se especializa en periodismo y gestión de la información en diferentes plataformas, además en promover y dirigir empresas informativas. En la Universidad de Piura, además del periodismo digital, incluye en su perfil la gestión para las empresas de comunicación y el desarrollo de las características del emprendedor periodístico.

Debido al vertiginoso avance de la ciencia y la tecnología, se han incrementado las posibilidades de llegar a los diversos públicos por los medios digitales. Los profesionales han encontrado un nuevo nicho de desarrollo, donde sobreviven los que realmente poseen competencias emprendedoras que se suman a las cognitivas, procedimentales y las actitudinales. El público necesita información valiosa y es importante que el periodista se lo provea.

El público busca cubrir los vacíos con temas específicos para resolver sus propias necesidades informativas, educativas y las de entretenimiento. A través del medio digital, el periodismo permite mantener el interés por la comunicación que se establece con el internauta (que lo aprueba o desaprueba en tiempo real). Esta inmediatez le permite innovar y así fidelizar a su público objetivo.

\section{Fuentes consultadas}

Alcaraz, R. (2011). “El emprendedor de éxito". Extraída el 9/VIII/2016 desde http:// es.slideshare.net/mikebsd/212783931-emprendedorexito

Arroyo, M. (2011). "La aproximación al perfil del periodista en la postmodernidad". Extraída el 9/VIII/2016 desde

http://www.razonypalabra.org.mx/N/N76/varia/2a\%20entrega/25_Arroyo_V76.pdf 
Barayar, A. (2007). "La innovación en las empresas de comunicación y relaciones públicas en la cultura 2.0”. Extraída el 9/VIII/2016 desde

http://www.contenidos.campuslearning.es/contenidos/376/curso/pdf/PLDC-DOCUMENTO\%20DE\%20APOYO-3.pdf

Casero, A. y Cullell, C. (2013). "Periodismo emprendedor. Estrategias para incentivar el autoempleo periodístico como modelo de negocio". Estudios sobre el mensaje periodístico, vol. 19, pp. 681-690. Extraída el 9/VIII/2016 desde http://revistas.ucm.es/index.php/ESMP/article/viewFile/42151/40130

Education and Culture Socrates - Tempus (2006). "Tuning Educational Structures in Europe. La contribución de las universidades al proceso de Bolonia". Extraída el 9/ VIII/2016 desde http:/www.unideusto.org/tuningeu/images/stories/documents/General Brochure_Spanish_version.pdf

Gómez, I. (2005). “Competencias profesionales: una propuesta de evaluación para las facultades de ciencias administrativas". Pedagogía universitaria. Educación y educadores. vol. 8, pp. 45-66. Extraída el 9/VIII/2016 desde

http://www.redalyc.org/articulo.oa?id=83400805

Larraín, A. y González, L. (2006). "Formación universitaria por competencias". Extraída el 9/VIII/2016 desde http://www.benv.edu.mx/reforma_curricular/MATERIALES_INDUCCION/LARRAIN_U_ANA_MARIA.pdf

Páez, D. y García, J. (2011). “Acercamiento a las características del universitario emprendedor en la unidad de emprendimiento empresarial de la Universidad Nacional de Colombia". Revista Escuela de Administración de Negocios, pp. 52-69. Extraída el 9/VIII/2016 desde http://www.redalyc.org/pdf/206/20623157005.pdf

\section{Salaverría, R.}

(coord.) (2016). Ciberperiodismo en Iberoamérica. Barcelona: Fundación Telefónica, Editorial Ariel. Extraída el 9/VIII/2016 desde

http://www.fundaciontelefonica.com/arte_cultura/publicaciones-listado/pagina-item-publicaciones/itempubli/479/

_(2004). "Diseñando el lenguaje para el ciberperiodismo". Chasqui (Revista Latinoamericana de Comunicación), núm. 86, pp. 38-45. Extraída el 9/VIII/2016 desde http://dadun. unav.edu/bitstream/10171/5060/1/Chasqui86-ramon.pdf

Secretaría Pyme y Desarrollo Emprendedor (2014). "Emprendiendo. Herramientas para emprendedores en formación”. Extraída el 12/VIII/2016 desde

http://es.slideshare.net/gewcordoba/web-emprendiendo

Serida, J. y otros (2015). Global Entrepreneurship Monitor: Perú 2013. Lima: Universidad ESAN. Extraída el 9/VIII/2016 desde http://www.esan.edu.pe/publicaciones/2015/02/27/ GEM-PERU-2013.pdf 
Serrano, C. (2011). "Emprendimientos periodísticos en Internet. Pistas para crear nuevos medios pensando en los usuarios". Extraída el 12/VIII/2016 desde

https://cibermensaje.files.wordpress.com/2012/03/2011_emprendimientos-periodc3adsticos-en-internet-pistas-para-crear-nuevos-medios-pensando-en-los-usuarios.pdf

Tobón, S. (2006). Formación basada en competencias. Madrid: Universidad Complutense de Madrid.

Yezers'ka, L. (2008). Ciberperiodismo en Perú. Análisis de los diarios digitales. Lima: Editorial San Marcos y Universidad de Piura. 